Seduced by "fakes" : Producing the excessive interplay of authentic/counterfeit from a Baudrillardian perspective

Hietanen, Joel

2020-03

Hietanen , J , Murray , J B , Sihvonen , A \& Tikkanen , H 2020 , ' Seduced by "fakes" :

Producing the excessive interplay of authentic/counterfeit from a Baudrillardian perspective '

, Marketing Theory , vol. 20 , no. 1, pp. 23-43 . https://doi.org/10.1177/1470593119870214

http://hdl.handle.net/10138/325698

https://doi.org/10.1177/1470593119870214

cc_by_nc_nd

acceptedVersion

Downloaded from Helda, University of Helsinki institutional repository.

This is an electronic reprint of the original article.

This reprint may differ from the original in pagination and typographic detail.

Please cite the original version. 


\title{
Seduced by 'fakes': Producing the excessive interplay of authentic/counterfeit from a Baudrillardian perspective
}

\begin{abstract}
Authenticity has often been considered to be a key theme in contemporary consumer culture. One of its manifestations is how branded market offerings can maintain authentic meanings, especially in a market increasingly saturated with counterfeit substitutes. By following a Baudrillardian perspective, we focus on fashion objects in the 'branded luxury' category to problematize the sanctity of the authentic/counterfeit distinction. We argue that marketing literature generally attempts to normatively maintain and impose the distinction in ways that obscure the complexities of this conceptual interplay. We posit that instead of normative accounts that attempt to sanctify the extant orders of global capitalist markets, literature on luxury consumption should instead recognize the excess of meaning in the semiotic interplay of commodified authentic/counterfeit meanings. Any view of morality in luxury consumption should thus recognize 'ambivalence' and 'seduction' as its intensive qualities.
\end{abstract}

Keywords: Branding, authenticity, counterfeit, Baudrillard, luxury, seduction 


\title{
Seduced by 'fakes': Producing the excessive interplay of authentic/counterfeit from a Baudrillardian perspective
}

\section{Introduction}

\begin{abstract}
We are no longer in a state of growth; we are in a state of excess. We are living in a society of excrescence [...] The boil is growing out of control, recklessly at cross purposes with itself, its impacts multiplying as the causes disintegrate (Jean Baudrillard)
\end{abstract}

How much faith do we continue to have in the myriad of signs set in motion by market offerings, and what is the interplay between the authentic and the counterfeit in how markets signify meanings in the form of branded commodities? If one was to outline a key sensibility of the 'late capitalist' society, then it would seem fitting to call it suspicion, even if this may seem ambiguous and often 'without a cause' (Cluley and Dunne, 2012; Stavrakakis, 2007). While the mistrust of all grand narratives arguably manifests itself in contemporary consumer culture, the 'value' of free-floating signs of consumption are in free play (Firat and Venkatesh, 1995; Jameson, 1991) and consumers as supposedly individualistic subjectivities are at liberty to construct meanings and manage their impressions in incessant performances of appearances (Cluley and Dunne, 2012; Jantzen et al., 2012). Consumers thus seem to be persistently subsumed into the commodity logic of consumer culture where incessant production of signs takes precedence (Cherrier and Murray, 2004), for there are no conceivable societal alternatives available (e.g., Arnould 2007; Fisher, 2009; Schiermer, 2011; Stavrakakis, 2007).

However, contemporary marketing literature is generally founded upon the assumption of a consumer culture where consumers seek elusive yet foundationally experiential meanings in market offerings (e.g., Arnould and Price, 2000; Arnould and Thompson, 2005), with the notion of 'authenticity' being deemed "the cornerstone of contemporary marketing practice" (Beverland, 2006: 251). In their quest for market-mediated meanings, consumers have thus generally been portrayed to be all but irresistibly 
drawn to authentic meanings in market offerings (Belk and Costa, 1998; Beverland and Farrelly, 2010; Grayson and Martinec, 2004; Hartmann and Ostberg, 2013; Holt, 2002; Rose and Wood, 2005). Consequently, understanding what constitutes authentic offerings and their illicit counterfeit counterparts, including imitations and fakes, has received broad academic interest. Regarding market offerings, the 'authentic' has been noted to stand for something of ambiguous and metaphysical nature, akin to a magical aura (Beverland and Farrelly, 2010; Dion and Arnould, 2011), an ethical imperative for consumers to follow (Chaudhry and Stumpf, 2011; Phau and Teah, 2009), as well as a genuine and legal connection with the brand an offering is marketed under (Commuri, 2009). The counterfeit offering, as distinct from the authentic branded product, is often seen simply as an illicit object that constitutes a 'menace' or 'scourge' to which only an immoral or ignorant consumer could be attracted (Bloch et al., 1993; Hamelin et al., 2013; Nill and Schultz, 1996).

While a clear authentic/counterfeit distinction generally continues to be propagated in marketing literature, work in both cultural studies (Pang, 2008; Yang, 2014) and cultural anthropology (Nakassis, 2012) has shown how authentic/counterfeit meanings are far from stable and can only be maintained and prescribed in ideological and normative terms. Building on this, we adopt Jean Baudrillard's critical social theory to assess the construction and maintenance of this binary logic in marketing scholarship and to explore how it persists as a normative framework that perpetuates the myth of authenticity in global markets. Baudrillard's semiotic perspective (also Cherrier and Murray, 2004; Østergaard and Fitchett, 2012) allows us to conceptually focus on the uneasy relationship between authentic and counterfeit in branded luxury markets as an inextricable system of signs.

We focus on branded luxury (or 'loud luxury') in the fashion market to offer an illustrative example characterized by strong brand visibility, aspirational conspicuousness, and 'exclusivity' marketed primarily to mass consumers (Bian and Forsythe, 2012; Han et al., 2010; Hilton et al., 2004). These 
are readily recognizable luxury products with highly visible logos or other aesthetic characteristics which are generally consumed for self-expression and presentation (Bian and Forsythe, 2012; Han et al., 2010), for example Louis Vuitton handbags with the embedded 'LV' monogram. As a segment, branded luxury illustrates how what seemingly used to be the conspicuous indulgence of the affluent and wealthy, has now increasingly translated into a cultural 'necessity' in mass markets (Kapferer and Bastien, 2009). The vastness and potential profitability of luxury markets has also brought about a parallel market for illicit counterfeit products which has been steadily growing alongside the luxury industry, and in no small terms (Hilton et al., 2004; Pang, 2008). In fact, the "International Chamber of Commerce estimates that seven percent of world trade is counterfeit goods" (Hilton et al., 2004: 345), with OECD (2016) figures making it a \$461 billion industry worldwide.

Our objectives are twofold. First, we assess how luxury markets as systems of signs have increasingly lost their ability to signify stable meanings (also Østergaard and Fitchett, 2012), and we explore how authentic/counterfeit distinctions inextricably intertwine in intensifying fashion where their separation is typically assumed in extant literature. Second, to problematize binary representations, we develop an argument regarding how branded luxury markets could be characterized semiotically as an excessive interplay of seduction and ambivalence. This allows us to also comment on the possibility of consumer morality and the normative positions generally held in the literature dealing with the notion of branded commodities deemed authentic.

\section{The promise of authenticity in luxury offerings}

The concept of luxury has a long and contested history in Western thought. Luxury was long regarded as a definite vice, the indulgence of a society prone to fail in vanity and superfluousity (Adams, 2012; Berry, 1994). The etymology of the term stems from a Latin lineage where "the word 'luxus' referred 
to effeminate sensuality, a passion for splendor and pomp. 'Luxuria' on the other hand, implied riot, excess, moral weakness, and extravagance, and was understood as a serious ethical failing” (Adams, 2012: 7-8). Consumption of luxury thus generally follows Veblen's (1889/1994) seminal formulation of the conspicuous acquisition of luxury goods for the public display of wealth. Veblen also described the distinction of social class as being fulfilled through consumption in order that "the members of each social stratum accept as their ideal of decency the scheme of life in vogue in the next higher stratum, and bend their energies to live up to that ideal" (p. 84). Thus, conspicuous consumption plays on significations of excess, involving certain degrees of wastefulness that would conventionally be deemed indecent. These signs can radiate status and prestige, and as such they are indeed 'costly symbols' (Yuran, 2016) that show one's ability to squander market value.

While Veblen's account provides interesting insights for the analysis of consumer culture, contemporary scholars have argued that the class system has largely fragmented in ways that have allowed new social movements and subcultures to produce identity resources for a myriad of genre distinctions (e.g., Jameson, 1991; Patsiaouras and Fitchett, 2012). Equally, the aristocratic masters have "changed into innumerable individuals pledged to a parody of sacrificial consumption, mobilized as consumers by the order of production" (Baudrillard, 1981: 119). The idea of luxurious consumption has become gradually diffused throughout affluent consumer markets and the luxury industry has been very keen to capitalize on such broad whims of vanity (Thomas, 2007).

In parallel to the growth of the luxury industry, research focusing on the marketing and management of luxury brands has recently been in notable upswing (e.g., Dion and Arnould, 2011; Tynan et al., 2010). Simultaneously, the boundaries of luxury have expanded beyond the traditional categories of fashion, perfumes and cosmetics, wines and spirits, and watches and jewelry to include automobiles, hotels, tourism, private banking, home furnishing, and airlines (Fionda and Moore, 2009), not to 
mention personal technologies and many more. The literature has, to date, primarily focused on the management of luxury as the production and marketing of products/services that have the capacity to signal status (Bian and Forsythe, 2012; Han et al., 2010). While luxury has been tangibly conceptualized as "product quality, aesthetic design, excellence of service, etc." (Dubois and Duquesne, 1993: 43), at the same time consumers have been seen to seek possession of these offerings for their symbolic characteristics (Tynan et al., 2010). Thus, any explicit value that these products offer has been noted to be "hidden in an impenetrable black box" of extravagance (Dubois and Paternault, 1995: 69).

It has been proposed that consumers are enthusiastic for authenticity in market offerings, perceiving this quality as a means by which to resist modernist rationalization so as to reenchant what has been seen as loss of tradition and secure identity positions (Belk and Costa, 1998; Beverland and Farrelly, 2010) and the generally "inauthentic nature of contemporary life" (Leigh et al., 2006: 481). The authenticity that luxury brands have been seen to offer consumers generally takes the form of essentialized meanings in their products such as brand heritage (Beverland, 2006; Fionda and Moore, 2009), an aura of uniqueness and artistry concerning how the offerings have been conceived (Dion and Arnould, 2011; Kapferer, 2014), and high quality and exclusivity (Beverland, 2006; Commuri, 2009; Tynan et al., 2010). This is in line with existing literature that has defined authenticity of market offerings as being context specific and based on consumers perceptions related to spatio-temporal connections to originality (indexicality), or physical reproduction that resembles the original (iconicity) convincingly (e.g., Grayson and Martinec, 2004). While the authenticity of one's identity and experiences in consumption have also been examined in the literature (Leigh et al., 2006; Peterson, 2005; Rose and Wood, 2005), luxury marketing literature primarily concentrates on the authenticity of market offerings and tends to treat authenticity as an attribute of commodities that can 
generally be managed and reproduced (see Beverland, 2005; Commuri, 2009; Dubois and Paternault, 1995; Napoli et al., 2014).

However, in the literature a highly tension-laden relationship seems to remain between the commodity market and the notion of authenticity itself, often noted for its paradoxical and ambiguous character (Beverland, 2005; Beverland and Farrelly, 2010; Hartmann and Ostberg, 2013; Peterson, 2005). While remaining problematic and elusive, it is nevertheless generally seen to consist of fleeting relationalities that are constantly negotiated by both consumers and managers (e.g., Beverland and Farrelly, 2010; Grayson and Martinec, 2004; Holt, 2002). To account for its elusive nature, it has been noted that managerial activities to market authenticity require extensive effort (Peterson, 2005) and often involve fabrication and hypocrisy in how marketing communications need to be orchestrated (Hartmann and Ostberg, 2013; Hilton et al., 2004; Holt, 2002). However, the construction of authenticity goes both ways, and thus the consumer is seen to play an active role in adeptly appropriating authentic significations and negotiating what are deemed acceptable levels of authenticity in their consumption (Askegaard et al., 2016; Arnould and Price, 2000; Rose and Wood, 2005).

One common thread that nevertheless seems to unify scholars across research streams is the assumption that consumers cannot get enough of market-mediated meanings of authenticity, and are thus continuously rewritten to strive for it in diverse contexts. We will later return to the highly problematic nature of this assumption of consumers' authenticity-seeking, but for the time being when we refer to what has become known as authentic versus counterfeit luxury we refer to market offerings where the former carries a signatory stamp of being a legally marketed commodity of a luxury brand house and where the latter is devoid of such affiliation (see Commuri, 2009; Pang, 2008). 


\section{Counterfeit market disruption}

Counterfeits refer to market offerings that illicitly emulate and resemble authentic goods (Grossman and Shapiro, 1988; Lai and Zaichkowsky, 1999). In defining different forms of counterfeiting, existing literature generally makes a distinction based on how much a counterfeit good resembles an original item and consequently how likely it is that it can be mistaken for an authentic item (Grossman and Shapiro, 1988; Hietanen et al., 2018; Le Roux et al., 2016). In doing so, deceptive counterfeits can be understood as replicas of original goods that are aimed at misleading the consumer (Grossman and Shapiro 1988; Le Roux et al., 2016), while non-deceptive counterfeits (or pirates) copy original goods but are produced under the auspices that the consumer will know that they are not authentic (Lai and Zaichkowsky, 1999). Finally, there are also 'knockoffs' and 'remixes' which only copy the design features of authentic goods (Hemphill and Suk 2009; Raustiala and Sprigman, 2006). In contrast to authentic luxury goods, what unifies the different forms of counterfeit is that they are generally perceived to be of lower product quality than authentic goods (Lai and Zaichkowsky, 1999; Tynan et al., 2010) and that they are devoid of the authenticating connection to the luxury brand (Commuri, 2009; Nia and Zaichkowski, 2000). Thus, for counterfeit consumers, "fakes are only a fictitious way of joining the elite" and "they never authentically reach the emotional state induced by genuine luxury product consumption" (Gabrielli et al., 2012: 579).

Within marketing literature, scholars focusing on counterfeit have found a diverse array of motives for its consumption. It has been argued that consumers are motivated to purchase counterfeit products for perceived price advantages (Grossman and Shapiro, 1988), due to perceptions of insignificant differences between the authentic and counterfeit offerings (Tom et al., 1998), how easily the counterfeit article can deceive the buyer (Staake et al., 2009), and how the buyer perceives the 
expectations of other consumers (Hoe et al., 2003; Kravets and Sandicki, 2014). Only a handful of studies in this literature have investigated consumers who explicitly seek out counterfeit items, and in such cases the consumer is typically seen as immoral (Chaudhry and Stumpf, 2011; Phau and Teah, 2009) or, in the most positive vein, as a savvy consumer who knows how to advantageously manipulate status games (Perez et al., 2010). Thus, there is a general assumption that counterfeit products are necessarily corrupt because they cause a profit risk for the producer of authentic offerings (Bian et al., 2016; Bloch et al., 1993; Commuri, 2009) and thereby constitute a 'menace' (Hamelin et al., 2013) that needs to be addressed decisively. Thus "the fight against counterfeiting needs to be led on two fronts; it is a legal battle to promote the integrity of the marketplace as well as a battle for the mind of the consumer" (p. 168).

While the idea of counterfeit is generally imbued with negative connotations, the literature remains curiously inconclusive on its role in markets. Hilton and colleagues (2004) demonstrated the ambiguity of luxury markets and questioned the defensibility of a stringent authentic/counterfeit binary. It has been also noted that consumers often have positive experiences with counterfeits (Key et al., 2013; Nia and Zaichkowski, 2000; Turunen and Laaksonen, 2011), and that counterfeits occasionally exceed the quality and availability of the authentic product (Hilton et al., 2004). Additionally, marketers of luxury goods have long engaged in the practices of mimicking the designs of other brand houses (Hemphill and Suk, 2009), outsourcing the manufacturing of branded luxury products to low-wage countries and sweatshops, and launching spin-off ready-to-wear brand extensions to attract a broader spectrum of consumers. Some luxury brands have even permitted their designs to be copied in order to gain publicity advantages (Hilton et al., 2004; Raustiala and Sprigman, 2006). While the notion of the rickety 10-dollar Rolex rip-off may remain familiar to Western consumers, the challenge of the high-quality counterfeit was already understood decades ago: 
In the past a counterfeit shirt would often fall apart or lose colour after the first wash, but there has been a significant improvement in the quality of fakes. Very often the fakes are made by the same manufacturer that is contracted to produce the original item. The copies are therefore indistinguishable from the genuine item, but are sold for less than half the price (OECD, 1998: 12)

Following these developments, some authors have argued that counterfeits may not devalue original brands (Nia and Zaichkowsky, 2000; Ritson, 2007), and can even be beneficial to them due to their ability to increase the desirability of their offerings by highlighting what is coveted (Hietanen et al., 2018; Key et al., 2013). However, these kinds of conclusions were already contested by Commuri (2009), who posited that consumers of authentic offerings have a keen tendency to shun broadly counterfeited brands in various ways.

These highly contradictory findings and conclusions suggest that the global market of counterfeit luxury is culturally far more complex than the clear conceptual binary often presented in the literature. What is more, if consumers were driven towards authenticity to the degree generally maintained in the literature, the growing popularity of counterfeit goods seems problematic to say the least. In the field of cultural studies, both Pang (2008) and Yang (2014) noted how the constant reproduction of the authentic/counterfeit narrative creates particular hegemonic orders in the global culture industry. What seems to be taking place is a process of word-shaping to produce particular market ideologies (Yang, 2014): a paradoxical game of celebrating innovation through the production of incremental copies that fall under the legislative orders of an identifiable brand veneer while denouncing the idea of copying itself (Pang, 2008). In the words of Yang (2014), to even speak of 'fakes' is to already demonstrate one's wholesale assent to "speak the language already prescribed by a symbolic system, made up by the legal lexicon of IPR" (p. 83). This is achieved particularly through intellectual property rights enforcement, popular literature, and, as we have seen, becomes readily echoed and rewritten in marketing scholarship.

In what follows, we will describe Baudrillard's semiotic analysis of commodity markets. This serves 
to ground our further subsequent analysis of how the authentic and the counterfeit operate as simultaneous signs that construct the very signification of branded luxury as an excess of meaning and a vertiginous simulation of desirability.

\section{Baudrillard's system of commodity markets under the excessive logic of the sign}

Various French scholars (e.g. Georges Bataille, Jean Baudrillard, Guy Debord, Jean-Francois Lyotard, and Paul Virilio) have noted how the meaningfulness of consumption is based on generally shared ideological positions and consumers' relations to excess of meaning without correspondence to utility (Pawlett, 1997). Here, we primarily focus on commodity consumption and the semiotic system of the fashion industry by following Jean Baudrillard (1929-2007). While Baudrillard has been criticized for his prophetic and polemic writing style, his influence on social and cultural theory has been widely recognized (Bishop and Phillips, 2007; Sandywell, 1995). His early work builds on Marxist ideas and remain relatively structuralist, but he later moved towards more explicitly postMarxian perspectives, writing in a more fatalistic fashion that shows a profound ambivalence in the face of the meaninglessness of consumer culture.

From Baudrillard's perspective, contemporary society is thoroughly underpinned by the logic of commodity consumption. This consumption is not seen as voluntary, but rather as a sort of 'forced enjoyment' that has become a duty of the 'competent' citizen (Baudrillard, 1998). All 'needs' in the market should be thus seen as mere manifestations of a shared cultural ideology that is not driven by reasoned thought, but rather by irrational desires that manifest fetishistically in commodity markets (Cluley and Dunne, 2012). Needs of consumption are thus mere operations of the semiotic system of signs that run amok without any reference to a reality beyond them. No-one needs to consume luxury and no-one needs to consume the sign of a branded commodity, but these signs are nevertheless 
prominently fetishized (Böhm and Batta, 2010; Cherrier and Murray, 2004). For Baudrillard, no human needs of consumption are given or natural. Needs are mere alibis for producing sign value, and its object is thus:

nothing but the different types of relations and significations that converge, contradict themselves, and twist around it, as such - the hidden logic that not only arranges this bundle of relations, but directs the manifest discourse that overlays and occludes it [...] it finds meanings with other objects, in difference, according to a hierarchical code of significations (Baudrillard, 1981: 63-64)

What we therefore have is a system of signs in free play, and in terms of markets only "a theory of the [culturally bound] ideological concept of need would make any sense" (p. 79). The signs of the dominant market order, brands, prestige, and social status are not superimposed upon a market actuality, but rather upon the very system of signification that produces the desiring relations in the commodity market itself (also Grandy and Mills, 2004; Yuran, 2016). This is the 'code' of consumption as an endless array of produced signifiers such as brands and prestige; simultaneously something that all consumers have to follow to achieve status and avoid social ostracism, but also a commonly shared secret that only becomes visible in its constant performative production in social settings embedded in consumption (Cherrier and Murray, 2004). As a signifying part of consumer culture, every market offering thus comes in the form of the commodity, and it is impossible to not take part in the 'code of consumption'; that is, to make purchases that are devoid of a brand veneer or are at the very least lifestyle choices (all the way from luxuries to groceries from a farmer's market).

Contemporary consumption is thus a labor of actively producing an endless array of signs of consumption in order to constantly display one's ability to create distinction and assert one's social status. The commodity market, consisting of essentially useless offerings, keeps itself in a cyclical operation by channeling consumption desires to social competition through distinction (Cluley and Dunne, 2012). The whole societal narrative of consumption thus relies on "an anxious anticipation, not that there may not be enough, but that there is too much, and too much for everyone" (Baudrillard, 1988: 30), where each person "is reputed to be continuously raising his rate of value production" 
(Baudrillard, 1981: 206). Instead of utility, a semiotic excess abounds creating its own 'hyperreality' of appearances that produce powerful realities in their own right in an ever-intensifying fashion (also Pawlett, 1997).

For Baudrillard, especially in his early work, what constitutes commodity fetishism in Western capitalist markets is deeply rooted in how objects of consumption acquire a secret that makes them desirable as autonomous objects devoid of how they came into being (also Böhm and Batta, 2010; Cluley and Dunne, 2012). In a market of no tangible meaning it is accumulation of the aura of this secret that claims precedence (also Campbell, 2005). This is also exhibited in a kind of mindless concern over the rate and quantity of accumulation where more, even of the same, can be seen as desirable (see Oushakine, 2000). Thus, the "commodity takes on a conspicuous phenomenology that hides its inner shallowness" (Schiermer, 2011: 92) and that points to how commodities stand for nothing else than the reproduction of their cyclical repetition "where one brand devours the other, each living for its own endless repetition" (Baudrillard, 1988: 17). Interestingly, when building his logic of the sign system in contemporary markets, Baudrillard refers to brands only in a passing fashion, almost as if their illusory nature and phantasmatic capacity to channel fetishistic desires was all too obvious, as "the brand name, which here plays a crucial role, imposes a coherent, collective vision, as though they were an almost indissociable totality, a series" (Baudrillard, 1998: 27). For a competent citizen, the sign of the brand must be understood as referring to particular monetary amounts, the destruction of which allows one to present oneself as a winner in the context of consumption by displaying signs borne by the relational object.

\section{The possibility of an 'authentic' commodity}

When consumption itself is understood as a system for producing endless arrays of market-based meanings within capitalist reproduction, the promise of authenticity signified by the branded luxury 
object deserves closer attention. For Baudrillard, the nature of authenticity follows cultural change as reflected in how objects were ideologically put to use in different historical eras. The cultural logic of simulation intensifies in stages, and through it Baudrillard (1994) analyses authenticity by questioning its very foundation. By outlining how signs become simulacra, that is, representations that bear no relationship to reality but construct reality in their own right, the ideological relation of the sign to reality has withered and become increasingly free-floating through four stages of abstraction:

it is the reflection of a profound reality;

it masks and denatures a profound reality;

it masks the absence of a profound reality;

it has no relation to any reality whatsoever: it is its own pure simulacrum (p. 6)

In the course of this increasing separation of the signifier and signified, faithful representation of the real first transmutes into an unfaithful copy that is incapable of representing reality. Still, there remains some 'connection' to reality. However, from here onwards a rift occurs and the sign becomes increasingly detached, morphing into a copy with no original. Now only artificial resemblances of the original remain. The final stage is a pure simulation where the image sheds all connections to its object. At this point simulation assumes a life of its own where it is no longer real or imaginary, but exchangeable with itself and thence equal to the real in its own right. The simulacrum is no longer connected to the real in any sense, but it is nevertheless powerfully productive in how it can produce ideology by taking part in the system of signification. Moving down this order, the contemporary luxury markets emerge from historical festive displays and rare sacred artefacts into a commodified cyclical order of detached signifiers of difference, where difference itself is the ultimate scarcity. With the advent of mass-media and the cultural industry, everything now operates not according to content, but as a hyperreal sign-creating ideological reality which no longer has any connection to the real. What we are left with is a game of appearances, intensified simulations of reality that have become more real than anything real beneath them and which have been irrevocably lost in any case in the consumer society (Singer, 1991). 
The form of a market offering coming into being is of paramount importance as well, and the manner in which an object takes on social signification is closely related to its production. Through mass marketing and industrial production, or the ability to produce repetitious and commodified market offerings, the ideological foundation of the original or the authentic shatters as it is increasingly impossible to point to a unique object (Østergaard and Fitchett, 2012). Nevertheless, here is where the fetish for the authentic originates in the form of a nostalgic spectral presence, or:

Non-discriminatory (the sign is nothing any longer if not competitive), relieved of every constraint, universally available, the modern sign nevertheless still simulates necessity by giving the appearance that it is bound to the world. The modern sign dreams of its predecessor, and would dearly love to rediscover the obligation in its reference to the real (Baudrillard, 2007: 51)

The sign of capitalist production thus operates by producing an alibi of real difference in society (status, prestige), which is often inscribed through a real connection to a heritage or nature (see Askegaard et al., 2016; Beverland, 2005; Grayson and Martinec, 2004), finding its value "as the simulacrum of "nature"” (Baudrillard, 2007: 51). In a similar fashion, the very underlying ideology of anything like a tangible connection to an authentic object of consumption is obscured by the very processes by which it is produced. In the industrial production of commodities, the mode shifts to not pointing to an original, but rather, in a fully Warholian fashion, connects to the very idea of technologies for the reproduction of commodified copies:

That is, the series: the very possibility of two or $n$ identical objects. The relation between them is no longer one of an original and its counterfeit, analogy or reflection, but is instead one of equivalence and indifference. In the series, objects become indistinct simulacra of one another and, along with objects, of the men that produce them. The extinction of the original reference alone facilitates the general law of equivalences, that is to say, the very possibility of production (Baudrillard, 2007: 55)

Here the link to an ontological notion of authenticity in industrial production of the 1900's breaks down in grand scale, for it is no longer only the possibility of technologies of reproduction we are dealing with, but an ideological shift in how to conceive the medium of the sign of the product through the potential of production. Thus, in contemporary commodity markets, it would seem that "all forms change from the moment that they are no longer mechanically reproduced, but conceived according 
to their very reproducibility" (Baurdillard, 2007: 56). This thought leads us through the orders of simulation, as:

There is no more counterfeiting of an original, as there was in the first order, and no more series as there were in the second [industrial production]; there are models from which all forms proceed according to modulated differences (Baudrillard, 2007: 56)

For Baudrillard, contemporary markets of commodity consumption fetishize authenticity precisely because authenticity is the very thing missing. In doing so, luxury companies attempt to instill uniqueness in their products by, for instance, trying to semiotically transform their offerings into unique pieces of art that would circumvent the problem of them being mass-produced or inscribing them with the logic of artistic authorship (see Dion and Arnould, 2011; Kapferer, 2014). However, when consumption objects become signs that only point back to the code of simulation itself, ambivalence "becomes structural equivalence, rendering social relations of production and consumption abstract and oblique" (Genosko, 1994: 5). Consequently, in Baudrillard's fatalistic view, all these intensifying market simulations of meaning are deeply attractive and seduce consumers in their excesses in a similar manner to the ways people become absorbed in intense ritualistic practices (Genosko, 1994; Singer, 1991), so as "to lose themselves in appearances" (Baudrillard, 1990: 67). The sign of ritualistic participation, when one is engulfed in such, is not representational, but rather a rush of unconscious desiring that is not to be 'understood' as "it delivers us from meaning" (Baudrillard, 1990: 137). For Baudrillard, in consumption, this is how intensive relations in the orders of simulation remain loose and afloat, as there is no moral grounding in the superfluous excess of the code itself. A prime example of this tendency is the allure of the fashion industry and how it recreates itself as a cyclical reproduction of the signs of authenticity and aesthetic innovation under brand veneers.

\section{On the fashion system}

For Baudrillard (2007) it is the very irrational cyclicality of fashion that makes it fascinating from the 
perspective of desiring consumption. We "enjoy the liquidation of meaning [...] enjoy this endless finality of fashion [where] all cultures play like simulacra in total promiscuity" (p. 87-88). For him, the entire signification of fashion floats like a spectral presence unconcerned with production or economic inequality. It simply exists for its own ever-moving play of signification in which it is cyclically reproduced in a cornucopia of signs showing that:

it knows nothing of value-systems, nor of criteria of judgement: good and evil, beauty and ugliness, the rational/irrational - it plays within and beyond these; it acts therefore as the subversion of all order (Baudrillard, 2007: 98)

The system of signification in commodity markets would fail if it could not continuously re-establish new alibis for the desirability of consumption. While eclectic and playful, these signs must firmly comply with this system of signification where every brand assumes a generally understood monetary value. If there is no spectacle of the ability to destroy economic value in consumer markets of commodified offerings, then neither is there the means of creating signs of social distinction, or "objects carrying costly symbols" (Yuran, 2016: 3). Where else would this be truer than in branded luxury where goods afford consumers all these opportunities through the high visibility of the brand itself. From this perspective, branded luxury goods are acquired for the 'autograph' of the designer, be it Louis Vuitton, Michael Kors, or Giorgio Armani.

Since authenticity is what the branded luxury commodity simulates, the brand 'autograph' of an authentic fashion product thus primarily constructs its worth. Being authentic therefore denotes the object's usefulness for constructing relations of social distinction (Hartmann and Ostberg, 2013). Simultaneously, this system of signs must constantly reproduce its claim for the latest authenticity through distinctions that perpetuate the need for further commodity exchange. Thus:

Truly beautiful, definitely beautiful clothing would put an end to fashion. The latter can do nothing but deny, repress and efface it - while conserving, with each new outing, the alibi of beauty (Baudrillard, 1981: 79)

The commodity market of branded luxury, as with fashion in general, must produce new 
conceptualizations of beauty and relevance to necessitate continuous consumption (also Dion and Arnould, 2011). For Baudrillard, fashion is thus closely coupled with the modernist notions of rupture and innovation as, "Under the sign of the commodity, time is accumulated like money - under the sign of fashion it is exhausted and discontinued in entangled cycles" (Baudrillard, 2007: 88), where the enchantment of its irrational playfulness with signs and cyclical velocity "remains the enchantment of the commodity, and, still further, the enchantment of simulation, the code and the law" (p. 95). This is to say that the fashion industry itself, in all its vertiginous cyclicality, operates only to produce and reproduce its own seductive semiotic excess.

What the break-down of grand narratives in the postmodern view of commodity markets suggests, is that the signifier-signified relationship with the product and authentic branded luxury is also increasingly fragmenting, even to a point where the "replacement of the object by the sign has led to a situation whereby distinctions between the real and fake, the original and the copy, no longer possess any point by which to justify such claims" (Hancock, 1999: 166-167). The growing popularity of counterfeit, especially in markets like fashion where the potential physical harm through product use is minimal and where the labor conditions at the place of production tend to be actively disregarded (Cluley and Dunne, 2012; Davies et al., 2012), is suggestive of this, even if counterfeit is consumed for a diverse array of market-mediated meanings. From a Baudrillardian perspective, what we instead see is ambivalence trumping the moral adherence to a normative market order in a grand scale with seduction as its driving force taking precedence in a dizzying fashion.

As shown by Nakassis (2012), consumers readily reappropriate signs of authenticity, but simultaneously continue to follow the code of how brands signify in general. These cultural practices of sign manipulation run in parallel with the efforts of brand houses to produce branded luxury products that increasingly focus on the sign of the brand printed in loud letters on short-lived garments 
(Hilton et al., 2004). Fashion items of branded luxury now come segmented to cater for aspirational consumption at almost any price point (Thomas, 2007) based all-but solely on the highly visible 'autograph', with quality and craftsmanship distant secondary concerns in production (also Hancock, 1999; OECD, 1998). What is more, the branded luxury market keeps continuously producing paradoxical signs that simultaneously cherish tradition and heritage, while producing offerings that are constantly on the 'hip' cutting edge (Askegaard et al., 2016; Brown et al., 2003; Thomas, 2007) to the point of ephemerality. Thus, the madness, magic, and even the product quality of luxury (Dion and Arnould, 2011) are signs in free play, an intensified loop of seduction and ambivalence, fetishistic desires and commodity narcissism (Cluley and Dunne, 2012). This is supported by literatures indicating that luxury brand houses (Hilton et al., 2004), legislative actors (Raustiala and Sprigman, 2006; Yang, 2014), and consumers themselves (Key et al., 2013; Nakassis, 2012; Yang, 2014) seem to be decreasingly concerned with protecting the sign of authenticity.

For Baudrillard, the promise of an authentic relation beyond the commodity system is precisely the relation the system cannot deliver. The authenticity of the branded object is a grand, desperate alibi of the commodity that is increasingly displaying the emptiness of any potential meaning it could contain and producing unhappy consumer subjectivities, even in relatively affluent contexts (see Jantzen et al., 2012; Shankar et al., 2006). In its attempt to valorize the authentic product it appears that marketing and business literatures operate here in an ideological tandem, maintaining a distinction that continues to sanctify the extant orders of commodity markets.

\section{Discussion: Authentic and counterfeit commodities in a market of signs}

The construction of consumption in markets of branded luxury

As we have seen, marketing scholarship has generally maintained a sharp distinction between 
authentic and counterfeit offerings, particularly in the context of luxury markets. A few notable exceptions notwithstanding (e.g., Hilton et al., 2004; Liao and Hsieh, 2013), much of this literature has focused on normatively ushering in a morality for consumers that is based on the normalization of business interests, both in terms of market ideology and related legislative practice. Making note of its origin, it is hardly surprising that this literature is generally more concerned with expediating market orders from managerialist perspectives rather than the complex cultural relations of signification in commodity markets. From a Baudrillardian perspective, however, branded luxury can be used to exemplify markets as systems of signs that simulate meaning, as it consists of simultaneous signs of uniqueness and ubiquity, quality and ephemerality, and a highly visible brand 'autograph'. In this mixture of producing branded signs, a branded luxury product is a highly paradoxical entity of contradictory appearances; overtly commodified 'authenticity' which simultaneously attempts to mask its commodity form as a market object.

Following Baudrillard, in order to function as signs in free play, branded fashion commodities appear to exist autonomously from their means of production, but they are fully embedded in their cultural system of signification (also Hancock, 1999). Thus, they are primarily referential in how they inhabit a place in the system of signification where brands vary according to the extent of the destruction of value related to their acquisition (Hietanen et al., 2018). By utilizing and exposing a rift in the stability of the system of exchange value, the idea of counterfeit seems to undermine the assumed semiotic system, akin to a foreign object. Its growing worldwide popularity thus represents a danger that the distinction between the signs of authentic branded luxury and counterfeit is not safe from ambiguity. Such dissolution of distinction and the potential losses of profits for luxury companies is a threat that many business scholars are eager to assume and warn against (see Commuri, 2009; Hamelin et al., 2013; Lai and Zaichkowsky, 1999). 
Yet, in an ironic fashion and following conventional marketing wisdoms, practitioners in brand houses producing luxury offerings have themselves been hard at work to eradicate the semiotic distinction between authentic and counterfeit products. This has come about through the implementation of conventional marketing management tools of rationalizing marketing activities with respect to increasing market share and market capitalization (Grandy and Mills, 2004), of expanding customer base through segmentation to virtually all price points, the mimicry of each other's designs by brand houses (Hemphill and Suk, 2009; Raustiala and Sprigman, 2006), producing goods in factory nightshifts, allowing the presence of counterfeit for marketing communications purposes (Hilton et al., 2004; Thomas, 2007), and blurring any connection between manufacturing and country-of-origin (country-of-design vs. country of manufacture) to virtual nonexistence (Pang, 2008). What seems to be easily forgotten in the literature is that there already is 'a global world factory', exemplified by Pang's (2008) work in the Chinese context, that produces both authentic and counterfeit products, and indeed often in the same factories. While simulated authenticity may still be the order of the day for the marketers of branded luxury, Baudrillard calls us to examine the interplay of authentic/counterfeit meanings from a more fatalistic perspective of markets where signs take part in an ever-increasing intensification and its seductive qualities.

\section{The seduction of counterfeit}

In contrast to a reified distinction between authentic and counterfeit offerings, a Baudrillardian interpretation would see the authentic/counterfeit interplay in luxury markets as a grand display of seduction and ambivalence in late capitalism (also Bogard, 1990; Singer, 1991). Based on this, we suggest that counterfeits are all too easily reduced to pure product attributes that readily enable making a clear distinction between authentic and counterfeit. Thus, while the idea of authenticity is often elevated in the literature to the level of 'magical' properties that persistently present to us nothing more than a 'black box of extravagance', counterfeit offerings are not spoken of in a similar 
sense. As they are not readily treated as a relational part of the code, counterfeit objects are typically seen to contain no value whatsoever. They have been deemed to occupy the rotten end of the binary.

Drawing from Baudrillard, what has been ushered to the background is the seductive power of counterfeit that produces an excessive symbolic dimension (of surface, appearance and play) where simulated distinctions start to blur in ever-increasing intensifications of capitalist production of artificial market meanings. In analyzing counterfeit, seduction seems especially fitting considering that it deals with the displacement of authenticity with artifice and appearance (Singer, 1991), or "an insanity borne by the vertiginous absence that unites them" (Baudrillard, 1990: 82). Seduction thus marks an enchanting and euphoric relation to excess and ritualistic symbolism that remains with us from previous societal forms (Genosko, 1994), a manic desire that is "supra-subjective and suprasensual [...] that consumes its subjects" (Baudrillard, 1990: 100). By reversing orders of signification, it enchants by replacing authenticity with a flux of artificial meanings in consumption (Hietanen et al., 2013). Thus, if the authentic market offering is awarded 'magical' qualities in the literature, the idea of counterfeit needs to be examined as equally radiant in its arrays of signification.

Following Baudrillard, instead of operating as fixed notions, the semiotic interplay between authentic and counterfeit products could be rather read as a relationship of an ever-increasing intensification of how the signs of authentic and counterfeit feed on each other and continue to accrue ambiguity in late capitalist markets of signs. What is at stake "is that the distinction between appearances and depths is collapsing, and that, as it were, from both sides" (Singer, 1991: 141). Thus, the authentic and the counterfeit arise from the ambivalence put into place by endless repetition of industrial production and become signs that chase each other in seductive interplay. This already manifests in multiple different forms such as the introduction of a brand called 'Louis Vuitton FAKE' which products are marketed as explicit fakes at prices exceeding the authentic offerings (see Nakassis, 2012). In similar 
fashion, the logo of the luxury streetwear brand 'Supreme' has been imitated by 'Supreme Italia' that now sell legal counterfeits in Spain and Italy, while initiating global collaborations with companies such as Samsung ${ }^{1}$. The irony is of course intensified in that the recognizable 'Supreme' logotype is in itself already an imitation of Barbara Kruger's propaganda posters from the late 1980's. Relatedly, communities of consumption have also spun around counterfeit luxury items where the art behind duplication is discussed (Key et al., 2013).

How does the semiotic flux of authentic/counterfeit become seductive? In a Baurdrillardian view of how signs circulate in the entire system of consumption, the semiotics of authentic and counterfeit cannot be separate, but rather form an intensifying semiotic relationship that starts to bleed into each other (Morris, 1988; Pawlett, 1997). In this sense, we can move beyond the typical separation maintained in the literature by intensifying the sign of the authentic (luxury) product to the point it becomes hyperauthentic, a point where it is only a repetition of industrial production adorning a marketed logo, effectively simulating its own simulation and thus increasingly dissolving its claims to authenticity and uniqueness. When becoming hyper, authentic luxury thus starts to signify all its relationships to outsourced and ethically problematic sweatshop production: fabricated brand messages of authentic craftsmanship and country-of-origin relations (Beverland, 2005; Hartmann and Ostberg, 2013). The hyperauthentic now points to all the baggage of being associated with a legally sanctioned brand as a commodity of industrial repetition. This semiotic undermines authenticity claims, and thus the idea of authenticity reveals how its distinction to counterfeit is an active production of signs in the market.

Simultaneously, counterfeit turns into hypercounterfeit through similar inversions of the entire web of signification. As a 'real' notion of authenticity is increasingly implausible in industrial production,

\footnotetext{
${ }^{1}$ https://edition.cnn.com/style/article/supreme-italia-legal-

fake/index.html?fbclid=IwAR0Stz0FHIRpVmfdnQhFKg0Rb4yhGMHlarFQTCoaJPR0IYOTwEcnkZPDsmU
} 
the sign of the counterfeit is intensified to the point where, in a sense, it becomes 'more authentic than authentic' by signifying how the idea of authenticity is a 'fake' fabrication in a consumer society marked by the commodity form. The sign of the counterfeit haunts the authentic by revealing its impossibility and thus offers a seductive relation of something that cannot be resolved (Hietanen et al., 2013). In a paradoxical interplay of signification, the hypercounterfeit thus offers an eerie glimpse of an authentic relationship now irrevocably lost in commodity capitalism. The sign of the hypercounterfeit is then the loss of authenticity itself; and thus its seductive power, through its alibi of resembling the authentic, is to deliver a relation that becomes a far 'more truthful' absence. As Morris (1988) notes, "Superbanality, for example, becomes fatal, and a superfatality would be banal" (p. 12). In a similar sense, the so-called authentic commodity is a 'banal seducer', but the counterfeit is a 'fatal seducer', for the authentic product can only signify by pointing towards fixities in attempts to scaffold its own meaning. Following Genosko (1994), it is in this sense the hypercounterfeit "is fatal inasmuch it is enigmatic" (p. 137), and thus is seductive by producing a fetishistic relation of excess meaning that is fascinating in its own right. While the sign of the authentic works as an alibi, a spurious reification of real meaning in the realm of the phantasmatic, the sign of the counterfeit is, on the other hand, increasingly playing its own semiotic games by accessing both the notion of authenticity and its inner emptiness - an intensifying exposure and thus a productive site of impossibility.

While a Baudrillardian view is necessarily speculative, he would likely point out that in contemporary markets all meaning is constructed and any 'real' significations have been overcome by simulations that are far more fascinating in their artificiality. In this sense, "the real, moreover, has never interested anyone [in terms of desiring...] The real, particularly in the present, is nothing more than the stockpiling of dead matter, dead bodies and dead language - a residual sedimentation" (Baudrillard, 1990: 46). It is never the real or some true nature of things that seduces, but rather 
appearances that work through their excess, an undefinable 'extra' that any situation can never disclose fully in its realness. In effect, authentic and counterfeit intensify their relations by frantically pointing towards the void in each other, and "it is this that is fascinating, this excess of reality, this hyperreality of things" (p. 29). Thus, as much as the analysis of luxury demands highlighting its symbolic qualities, so does the analysis of counterfeit demand that we acknowledge that they are much more than physical products. However, acknowledging this means that we have to accept that defining counterfeits as mere inferior copies does not suffice and that their interplay of meaning is far from clear cut.

In practice, similar notions are already in play in the luxury market where the distinction between branded luxury and non-branded goods is made on the basis of the existence of counterfeits, and where not being counterfeited has been seen as an inherent problem for a luxury brand (El Harbi and Grolleau, 2008²; Ritson, 2007). Without counterfeit (or its constant reminder) as part of the sign system, the claim of authenticity becomes increasingly vacuous, void of meaning. Thus, in literatures keen to maintain normative market orders, the authentic position needs always to be constructed as being under threat and in danger of being exposed. For the extant logic of the consumer market to maintain itself, it is not simply the desire for products and advertising that must be produced, but equally the very ideology of consumption and the consumer; his/her desire must be taught (Böhm and Batta, 2010; Cluley and Dunne, 2012). In this sense, there are sound ideological reasons for the seemingly unremitting efforts to maintain the distinction as sacrosanct in efforts to rationalize and discipline the consumer. Writing the market as a simple binary to support market-driving ideologies may well be a seductive practice in its own right in the sense that the code of luxury seduces too, and marketing researchers are naturally living the code themselves.

\footnotetext{
${ }^{2}$ In the example of El Harbi and Grolleau (2008), the luxury mobile phone company Vertu produced an array of marketing communications based on displaying the attractiveness of the brand in terms of how commonplace their counterfeiting is
} 


\section{Consumer morality}

Baudrillard's claim is that constructing the modernist distinction between the object and subject also necessitated the creation of (an ideological) relation between them; the need to consume to 'fill' the separation of the signifier-signified. Once consumption is understood as the labor of active production of signs in the market, a shift has occurred that problematizes not only how such needs are fulfilled, but also "the dynamic that emerges during the process of consumption both between the subject and the object of consumption and within the subject of consumption" (Oushakine, 2000: 98). This recognition allows us to increasingly think in terms not only of a complete subject with certain purposes and desires to be met, but also what kinds of subjectivities these kinds of relations keep on constructing.

It would seem that the contradiction in much of the literature emanating from business scholarship dealing with counterfeit remains; whilst the free will of the consumer in their consumption activities is much vaunted, the script that is continuously rewritten is one in which only one course of action is acceptable (Gabriel, 2015). Indeed, the desire for consuming has become akin to a moral order: a requirement of citizenship. By conceptualizing the luxury market as a sign system, we can see that the general code of the market for consumer subjectivities may be pervasive, but the signs therein have no predestined fixity.

So why might consumers be unwilling to comply with the normatively imposed authentic/counterfeit binary? Following critical scholarship, we would like to suggest that consumers are increasingly aware of the emptiness and outright falsity of the marketers' claims of authenticity (e.g., Baudrillard, 1998; Stavrakakis, 2007). Nevertheless, as Cluley and Dunne (2012) point out, consumption is not only fully embedded in culture, but can be enjoyed and desired even in all its inequalities, injustices 
and alienation, as one generally has no plausible access to valid post-capitalist alternatives (Cova et al., 2011; Fisher, 2009; Schiermer, 2011). Once this is recognized, and indeed it is understood that luxury brand houses have done little to deserve the moral authority that is hoped to channel consumption desire, the possibility of the incessant combining of signs from both authentic and counterfeit forms of market offerings arises. They are marked by increasing ambivalence but are wrought with seductive intensities; some of them seemingly calculative and deceptive, some of them cynical, some of them playful, whatever can be conceptually codified from how desires manifest in consumption.

Further, the seductive interplay of authentic and counterfeit also casts their morality in an eerie light. While the maintenance of a stark distinction between these two generates possibilities of moral judgement, their intensification dispenses moral orders since seduction is always ethically ambivalent (Baudrillard, 1990; also Genosko, 1994; Singer, 1991). While the intensification of counterfeit squarely points to the shallowness of authenticity claims, the same can now be said of the hyperauthentic since it starts pointing to all the moral failings of luxury, be it simply repetitious mass production adjourned with fabricated messages of authentic craftmanship, the burning of inventory to maintain scarcity ${ }^{3}$, or sweatshop child labor. Thus, seduction becomes the moral malediction of the authentic since it points us to where we started from - that luxury has no share in morality in the first place.

While the all-encompassing totality of Baudrillard's code of consumption can be questioned, it is nevertheless important to note that we are not suggesting that consumers are engaging in resistance when they negotiate the code of branded luxury (also Salzer-Mörling and Strannegård, 2007). Resistance would entail agency and an inclination tow ards activity, but seduction as a driver of desire

\footnotetext{
${ }^{3}$ https://www.bbc.com/news/business-44885983
} 
occludes such a position, as it operates through intensities that attract narcissistic 'weaknesses' and turns them into ritualistic mania (Genosko, 1994; also Cluley and Dunne, 2012). It thus does not mark a 'challenge' to be answered, but rather losing oneself in a "vertigo that comes of being absorbed in a recurrent fate" (Baudrillard, 1990: 148). As Baudrillard would have it, it is far more likely that suspicion itself is fully operating as part of the code and proliferates in ways that are far more culturally complex than the semiotic binary that the dedicated literature tends to rewrite. When brand meanings are appropriated by consumers, the general code of commodity capitalism is generally not questioned, only its simplicity and hierarchical linearity in and across market cultures (Nakassis, 2012). Marked by ambivalence, these repetitions of consumer desire may not simply continue to blindly fall in line with normative orders of moral behavior in a market keen to demonstrate its absence. In a culture of consumption of seductive excesses, over-coded and superfluous, the production of signs takes precedence, and, following Baudrillard, the 'moral' citizen is ideologically bound to a mad desiring dash of constantly increasing his/her own level and rate of production. A moral compass, imposed upon or not, has little to do with the seductive lure of the code. When the distinction between authentic/counterfeit continues to be constructed as rational choice with an obvious moral answer, whose signs are then for sale, and who is the authority that dictates the terms of desire?

\section{References}

Adams WH (2012) On Luxury: A Cautionary Tale. Washington, DC: Potomac Books.

Arnould EJ (2007) Should consumer citizen escape the market?. The ANNALS of the American Academy of Political and Social Science 611(1): 96-111.

Arnould EJ and Price LL (2000) Authenticating Acts and Authoritative Performances: Questing for 
Self and Community. In: Ratneshwar, S, Mick, DG and Huffman C (eds) The Why of Consumption: Contemporary Perspectives on Consumers Motives, Goals, and Desires. London: Routledge, pp.140163.

Arnould EJ and Thompson CJ (2005) Consumer culture theory (CCT): Twenty years of research. Journal of Consumer Research 31(4): 868-882.

Askegaard S, Kristensen DB and Ulver S (2016) 'Authentic food' and the double nature of branding. In: Cappellini B and Parsons E (eds) The Practice of the Meal: Food, Families and the Market Place. London: Routledge, pp.15-30.

Baudrillard J (1981) For the Critique of the Political Economy of the Sign. St. Louis, MO: Telos Press.

Baudrillard J (1988) Selected Writings. Stanford, CA: Stanford University Press.

Baudrillard J (1990) Seduction. Montreal: New World Perspectives.

Baudrillard J (1998) The Consumer Society. London: Sage.

Baudrillard J (1994) Simulacra and Simulation. Ann Arbor, MI: Michigan University Press.

Baudrillard J (2007) Symbolic Exchange and Death. Thousand Oaks, CA: Sage.

Belk RW and Costa JA (1998) The mountain man myth: A contemporary consuming fantasy. Journal 
of Consumer Research 25(3): 218-240.

Berry CJ (1994) The Idea of Luxury. New York, NY: Cambridge University Press.

Beverland MB (2005) Crafting brand authenticity: The case of luxury wines. Journal of Management Studies 42(5): 1003-1029.

Beverland MB (2006) The 'real thing': Branding authenticity in the luxury wine trade. Journal of Business Research 59(2): 251-258.

Beverland MB and Farrelly FJ (2010) The quest for authenticity in consumption: Consumers' purposive choice of authentic cues to shape experienced outcomes. Journal of Consumer Research 36(5): 838-856.

Bian Q and Forsythe S (2012) Purchase intention for luxury brands: A cross cultural comparison. Journal of Business Research 65(10): 1443-1451.

Bian X, Wang KY, Smith A and Yannopoulou N (2016) New insights into unethical counterfeit consumption. Journal of Business Research 69(10): 4249-4258.

Bishop R and Phillips J (2007) Baudrillard and the evil genius. Theory, Culture \& Society 24(5): 135145.

Bloch PH, Bush RF and Campbell L (1993) Consumer "accomplices" in product counterfeiting. Journal of Consumer Marketing 10(4): 27-36. 
Bogard W (1990) Closing down the social: Baudrillard's challenge to contemporary sociology. Sociological Theory 8(1): 1-15.

Bosker B (2013) Original Copies. Honolulu, HI: University of Hawaii Press.

Brown S, Sherry JF Jr and Kozinets RV (2003) Teaching old brands new tricks: Retro branding and the revival of brand meaning. Journal of Marketing 67(3): 19-33.

Böhm S and Batta A (2010) Just doing it: Enjoying commodity fetishism with Lacan. Organization 17(3): 345-361.

Campbell C (2005) The Romantic Ethic and the Spirit of Modern Consumerism. Oxford: Alcuin Academics.

Chaudhry PE and Stumpf SA (2011) Consumer complicity with counterfeit products. Journal of Consumer Marketing 28(2): 139-151.

Cherrier H and Murray JB (2004) The sociology of consumption: The hidden facet of marketing. Journal of Marketing Management 20(5-6): 509-525.

Cluley R and Dunne S (2012) From commodity fetishism to commodity narcissism. Marketing Theory 12(3): 251-265.

Commuri S (2009) The impact of counterfeiting on genuine-item consumers' brand relationships. 
Journal of Marketing 73(3): 86-98.

Cova B, Dalli D and Zwick D (2011) Critical perspectives on consumers' role as 'producers': Broadening the debate on value co-creation in marketing processes. Marketing Theory 11(3): 231241.

Davies IA, Lee Z and Ahonkhai I (2012) Do consumers care about ethical-luxury?. Journal of Business Ethics 106(1): 37-51.

Dion D and Arnould EJ (2011) Retail luxury strategy: Assembling charisma through art and magic. Journal of Retailing 87(4): 502-520.

Dubois B and Duquesne P (1993) The market for luxury goods: Income versus culture. European Journal of Marketing 27(1): 35-44.

Dubois B and Paternault C (1995) Understanding the world of international luxury brands: the "dream formula". Journal of Advertising Research 35(4): 69-77.

El Harbi S and Grolleau G (2008) Profiting from being pirated by 'pirating' the pirates. Kyklos 61(3): $385-390$.

Fionda AM and Moore CM (2009) The anatomy of the luxury fashion brand. Journal of Brand Management 16(5-6): 347-363.

Firat AF and Venkatesh A (1995) Liberatory postmodernism and the reenchantment of consumption. 
Journal of Consumer Research 22(3): 239-267.

Fisher M (2009) Capitalist Realism: Is there No Alternative?. Winchester: Zero Books.

Gabriel Y (2015) Identity, choice and consumer freedom-The new opiates? A psychoanalytic interrogation. Marketing Theory 15(1): 25-30.

Gabrielli V, Grappi S and Baghi I (2012) Does counterfeiting affect luxury customer-based brand equity?. Journal of Brand Management 19(7): 567-580.

Genosko G (1994) Baudrillard and Signs: Signification Ablaze. London: Routledge.

Grandy G and Mills AJ (2004) Strategy as simulacra? A radical reflexive look at the discipline and practice of strategy. Journal of Management Studies 41(7): 1153-1170.

Grayson K and Martinec R (2004) Consumer perceptions of iconicity and indexicality and their influence on assessments of authentic market offerings. Journal of Consumer Research 31(2): 296312.

Grossman GM and Shapiro C (1988) Counterfeit-product trade. American Economic Review 78(1): $59-75$.

Hamelin N, Nwankwo S and El Hadouchi R (2013) 'Faking brands': Consumer responses to counterfeiting. Journal of Consumer Behaviour 12(3): 159-170. 
Han YJ, Nunes JC and Drèze X (2010) Signaling status with luxury goods: The role of brand prominence. Journal of Marketing 74(4): 15-30.

Hancock P (1999) Baudrillard and the metaphysics of motivation: A reappraisal of corporate culturalism in the light of the work and ideas of Jean Baudrillard. Journal of Management Studies 36(2): 155-175.

Hartmann BJ and Ostberg J (2013) Authenticating by re-enchantment: The discursive making of craft production. Journal of Marketing Management 29(7-8): 882-911.

Hemphill CS and Suk J (2009) The law, culture, and economics of fashion. Stanford Law Review 61(5): 1147-1199.

Hietanen J, Schouten JW and Vaniala I (2013) Consuming the contradiction. Advances in Consumer Research 41: videography.

Hietanen J, Mattila P, Sihvonen A and Tikkanen H (2018) Paradox and market renewal: Knockoffs and counterfeits as doppelgänger brand images of luxury. Marketing Intelligence \& Planning 36(7): $750-763$.

Hilton B, Choi CJ and Chen S (2004) The ethics of counterfeiting in the fashion industry: Quality, credence and profit issues. Journal of Business Ethics 55(4): 343-352.

Hoe L, Hogg G and Hart S (2003) Faking it: Counterfeiting and consumer contradictions. European Advances in Consumer Research 6: 60-67. 
Holt DB (2002) Why do brands cause trouble? A dialectical theory of consumer culture and branding. Journal of Consumer Research 29(1): 70-90.

Jameson F (1991) Postmodernism: Or, the Cultural Logic of Late Capitalism. London: Verso.

Jantzen C, Fitchett J, Østergaard P and Vetner M (2012) Just for fun? The emotional regime of experiential consumption. Marketing Theory 12(2): 137-154.

Kapferer J-N (2014) The artification of luxury: From artisans to artists. Business Horizons 57(3): $371-380$.

Kapferer J-N and Bastien V (2009) The specificity of luxury management: Turning marketing upside down. Journal of Brand Management 16(5-6): 311-322.

Key TM, Boostrom RE, Adjei MT and Campbell DA (2013) Watch out: Themes in timepiece communities of counterfeit consumption. Journal of Consumer Behaviour 12(4): 307-317.

Kravets O and Sandikci O (2014) Competently ordinary: New middle class consumers in the emerging markets. Journal of Marketing 78(4): 125-140.

Lai KKY and Zaichkowsky JL (1999) Brand imitation: Do the Chinese have different views?. Asia Pacific Journal of Management 16(2): 179-192.

Le Roux A, Bobrie F and Thébault M (2016) A typology of brand counterfeiting and imitation 
based on a semiotic approach. Journal of Business Research 69(1): 349-356.

Liao CH and Hsieh IY (2013) Determinants of consumer's willingness to purchase gray-market smartphones. Journal of Business Ethics 114(3): 409-424.

Nakassis CV (2012) Brand, citationality, performativity. American Anthropologist 114(4): 624-638.

Napoli J, Dickinson SJ, Beverland MB and Farrelly F (2014) Measuring consumer-based brand authenticity. Journal of Business Research 67(6): 1090-1098.

Nia A and Zaichkowsky JL (2000) Do counterfeits devalue the ownership of luxury brands? Journal of Product \& Brand Management 9(7): 485-497.

Nill A and Shultz CJ (1996) The scourge of global counterfeiting. Business Horizons 39(6): 37-43.

OECD (1998) The Economic Impact of Counterfeiting. Available at:

https://www.oecd.org/sti/ind/2090589.pdf (accessed 17 June 2013).

OECD (2016) Global trade in fake goods worth nearly half a trillion dollars a year - OECD \& EUIPO. Available at: http://www.oecd.org/industry/global-trade-in-fake-goods-worth-nearly-half-a-trilliondollars-a-year.htm (accessed 8 April 2018).

Oushakine SA (2000) The quantity of style: Imaginary consumption in the new Russia. Theory, Culture \& Society 17(5): 97-120. 
Pang L (2008) 'China who makes and fakes': A semiotics of the counterfeit. Theory, Culture \& Society 25(6): 117-140.

Patsiaouras G and Fitchett JA (2012) The evolution of conspicuous consumption. Journal of Historical Research in Marketing 4(1): 154-176.

Pawlett W (1997) Utility and excess: The radical sociology of Bataille and Baudrillard. Economy and Society 26(1): 92-125.

Perez ME, Castaño R and Quintanilla C (2010) Constructing identity through the consumption of counterfeit luxury goods. Qualitative Market Research: An International Journal 13(3): 219-235.

Peterson RA (2005). In search of authenticity. Journal of Management Studies 42(5): 1083-1098

Phau I and Teah M (2009) Devil wears (counterfeit) Prada: A study of antecedents and outcomes of attitudes towards counterfeits of luxury brands. Journal of Consumer Marketing 26(1): 15-27.

Raustiala K and Sprigman C (2006) The piracy paradox: Innovation and intellectual property in fashion design. Virginia Law Review 92(8): 1687-1777.

Ritson M (2007) Fakes can genuinely aid luxury brands. Marketing 25: 21.

Rose RL and Wood SL (2005) Paradox and the consumption of authenticity through reality television. Journal of Consumer Research 32(2): 284-296. 
Salzer-Mörling M and Strannegård L (2007) Ain’t misbehavin’ - Consumption in a moralized brandscape. Marketing Theory 7(4): 407-425.

Sandywell B (1995) Forget Baudrillard?. Theory, Culture \& Society 12(4): 125-152.

Schiermer B (2011) Quasi-objects, cult objects and fashion objects: On two kinds of fetishism on display in modern culture. Theory, Culture \& Society 28(1): 81-102.

Shankar A, Whittaker J and Fitchett JA (2006) Heaven knows I'm miserable now. Marketing Theory 6(4): 485-505.

Singer B (1991) Baudrillard's seduction. CTheory 15(1-3): 135-139.

Staake T, Thiesse F and Fleisch E (2009) The emergence of counterfeit trade: A literature review. European Journal of Marketing 43(3/4): 320-349.

Stavrakakis Y (2007) The Lacanian Left: Essays on Psychoanalysis and Politics. New York, NY: SUNY Press.

Thomas D (2007) Deluxe-How Luxury Lost its Luster. London: Penguin Books.

Tom G, Garibaldi B, Zeng Y and Pilcher J (1998) Consumer demand for counterfeit goods. Psychology \& Marketing 15(5): 405-421.

Turunen LM and Laaksonen P (2011) Diffusing the boundaries between luxury and counterfeits. 
Journal of Product \& Brand Management 20(6): 468-474.

Tynan C, McKechnie S and Chhuon C (2010) Co-creating value for luxury brands. Journal of Business Research 63(11): 1156-1163.

Veblen T (1889/1994) The Theory of the Leisure Class. New York, NY: Penguin Books.

Yang F (2014) China's 'Fake' Apple Store: Branded space, intellectual property and the global culture industry. Theory, Culture \& Society 31(4): 71-96.

Yuran N (2016) Meaningful objects or costly symbols? A Veblenian approach to brands. Theory, Culture \& Society 33(6): 25-49.

Østergaard P and Fitchett J (2012) Relationship marketing and the order of simulation. Marketing Theory 12(3): 233-249. 